\title{
The Relationship between Iron Deficiency and Febrile Convulsion: A Case-Control Study
}

\author{
Mohammad Reza Sharif ${ }^{1}$, Davood Kheirkhah ${ }^{1}$, Mahla Madani ${ }^{2}$ \& Hamed Haddad Kashani ${ }^{3}$ \\ ${ }^{1}$ Department of Pediatrics, Kashan University of Medical Sciences, Kashan, Iran \\ ${ }^{2}$ Student Research Committee, Kashan University of Medical Sciences, Kashan, Iran \\ ${ }^{3}$ Anatomical Sciences Research Center, Kashan University of Medical Sciences, Kashan, Iran \\ Correspondece: Mahla Madani, Student Research Committee, Kashan University of Medical Sciences, Kashan, \\ Iran. E-mail: madani.mahla@yahoo.com
}

Received: December 2, 2014 Accepted: May 19, 2015 Online Published: June 25, 2015

doi:10.5539/gjhs.v8n2p185 URL: http://dx.doi.org/10.5539/gjhs.v8n2p185

\begin{abstract}
Introduction: Febrile seizure is among the most common convulsion disorders in children, which strikes $2 \%$ to $5 \%$ of children between 3 to 60 months of age. Some studies have reported that iron deficiency could be a risk factor for febrile seizure. The present study was conducted to compare the rate of iron deficiency anemia in febrile children with and without seizure.

Materials and Methods: This case-control study evaluated 200 children aged 6-60 month in two 100 person groups (febrile seizure and febrile without convulsion) in Kashan. The CBC diff, serum iron and TIBC were done for all of participants. Diagnosis of iron deficiency anemia based on mentioned tests.

Results: No significant differences were found in two groups regarding to the age, gender, and the disease causing the fever. The presence of iron deficiency anemia was $45 \%$ in the convulsion group and $22 \%$ in the group with fever without convulsion. The Chi Square test indicated a significant difference between two groups.

Conclusions: The findings suggest that a considerable percentage of children having febrile seizure suffer from iron-deficiency anemia and low serum iron. This means the low serum iron and presence of anemia can serve as a reinforcing factor for the febrile seizure in children.
\end{abstract}

Keywords: iron deficiency anemia, iron deficiency, fever, febrile seizure, children

\section{Introduction}

Febrile seizure is the most common convulsive disorder in children which strikes $2 \%$ to $5 \%$ of children between 3 to 60 months of age. Some of the recent studies have reported that iron deficiency could be a risk factor for febrile seizure because the latter is more common in children under two years and iron deficiency anemia is also common in children of the same age. Due to the presence of iron in the hemoglobin structure, it plays a crucial role in the transport of oxygen to different tissues such as the brain (Østergaard 2009; Jones et al., 2007; Kheirkhah et al., 2013; Kliegman 2011; Pisacane et al., 1996). Iron deficiency reduces the metabolism of some neurotransmitters (Lozoff et al., 2006; Parks et al., 1989). Several lines of evidence led to the hypothesis that iron deficiency can have a role in the onset of a convulsion. However, the studies carried out so far have reported conflicting results. Some studies have reported that in the patients with iron deficiency, febrile convulsion is significantly higher than that in the control group (Ur-Rehman et al., 2005; Daoud et al., 2002; Hartfield et al., 2009; Momen et al., 2010). On the contrary, some authors have concluded that the risk of febrile seizure in anemic children seems to be less than that in children with no febrile seizure (Talebian et al., 2006) and that iron deficiency can be a protective mechanism against convulsions by increasing the convulsion threshold (Kobrinsky et al., 1995). Other studies have shown that iron deficiency plays no role in pediatric febrile seizures (Salehi et al., 2009; Amirsalari et al., 2010). Since the relationship between iron deficiency and febrile seizure is not yet determined, chance or other unknown factors can be considered as causes (Bidabadi et al., 2009). Considering the above results and since no study has been conducted in Kashan, Iran on the mentioned relationship, the present study was conducted to compare the iron deficiency anemia in the febrile seizure children to those in the febrile patients without convulsion. 


\section{Methods and Materials}

This is a case-control study, which was conducted during 2012 in Kashan, on 200 participants in two 100-person groups: febrile seizure and fever without convulsion. The case group consisted of children, aged 6 months to 5 years, with normal development, who were taken to the hospital for the first febrile seizure. Samples with electrolyte imbalance (sodium, calcium, etc.), hypoglycemia, meningitis, encephalitis, shigellosis, neurological deficiencies and history of seizure (with or without fever) were excluded from the study. For each child with febrile convulsion, a child aged 6-60 months was selected in the control group with a similar febrile illness, but didn't show seizure. In all cases, after the goals and the voluntary nature of the study were explained to the parents, they were asked to sign the consent form. Personal information about the children, including age, gender and family history of seizure were collected from parents through an interviewed questionnaire. In both groups, body temperature was also measured and recorded by axillary method. The blood tests of CBC diff, serum Iron, and TIBC were conducted. Anemia was defined as $\mathrm{Hb}<10.5 \mathrm{~g} / \mathrm{dl}$ for children from the age of six months to two year olds, and $\mathrm{Hb}<11.5 \mathrm{~g} / \mathrm{dl}$ for $2-5$ years old children. The normal level of serum iron was determined as $\mathrm{Fe}>$ $40 \mu \mathrm{g} / \mathrm{dl}$ for children younger than one year and $\mathrm{Fe}>50$ for children over one year. The normal range of TIBC was considered $210-430 \mu \mathrm{g} / \mathrm{dl}$. The normal transferrin saturation percentage was considered higher than 15 percent (Kliegman, 2011; Oski et al., 2008). Diagnosis of iron deficiency anemia based on mentioned criteria. The collected data were analyzed using descriptive statistics, including frequency, percentage, standard deviation and mean, as well as analytical statistics, such as Chi Square to compare qualitative variables; the Analysis of variance test and T-test to compare quantitative variables.

\section{Results}

When studying the personal characteristics, no significant differences were found in two groups in terms of age, gender. Regarding the family history of convulsion, there was a significant difference between the study groups. Furthermore, the febrile convulsion group and the group of fever without convulsion had no significant difference in terms of the disease causing the fever. The diseases causing the fever in both groups were respiratory and digestive infections (Table 1).

Table 1. Personal information of patients under study in two groups

\begin{tabular}{lllll}
\hline \multicolumn{1}{c}{ Group } & & $\begin{array}{l}\text { Febrile seizure } \\
\mathbf{n}(\%)\end{array}$ & $\begin{array}{l}\text { Fever without convulsion } \\
\mathbf{n}(\%)\end{array}$ & PV \\
\hline \multirow{2}{*}{ Gender } & Boy & $62(62)$ & $56(56)$ & 0.38 \\
& Girl & $38(38)$ & $44(44)$ & \\
Family history of seizure & Yes & $27(27)$ & $10(10.1)$ & 0.002 \\
& No & $73(73)$ & $89(89.9)$ & \\
Infectious disease type & Respiratory & $64(64)$ & $60(60)$ & 0.49 \\
& Gastroenteritis & $33(33)$ & $38(38)$ & \\
Age (month) * & Others & $3(3)$ & $2(2)$ & 0.77 \\
\hline
\end{tabular}

* Mean \pm standard deviation.

In the febrile convulsion group, most of the members (72\%) belonged to the age group of less than two years ( $18 \%$ were less than one year, $36 \%$ between 1 and 2 years old, $25 \%$ between two and three, and $21 \%$ over three years). The average of serum Iron and TIBC were significantly different in two groups (Table 2). 
Table 2. Mean and standard deviation of different indices of iron deficiency anemia in children under study

\begin{tabular}{llll}
\hline \multicolumn{1}{c}{ Group } & Febrile Seizure & Fever without convulsion & PV \\
iron anemia & $11.45 \pm 1.34$ & $11.82 \pm 1.45$ & 0.062 \\
Hb & $42.62 \pm 28.02$ & $52.45 \pm 34.76$ & 0.028 \\
Serum iron & $393.22 \pm 39.61$ & $345.94 \pm 26.82$ & 0.0001 \\
TIBC & $12.77 \pm 8.26$ & $14.41 \pm 10.60$ & 0.22 \\
\hline
\end{tabular}

The presence of iron deficiency anemia was $45 \%$ in the convulsion group, $22 \%$ in the group with fever without convulsion. The Chi Square test indicated a significant difference between the groups (Table 3).

Table 3. Frequency distribution of iron deficiency anemia in the children of two groups

\begin{tabular}{llll}
\hline Group & Positive n(\%) & Negative n(\%) & PV \\
\cline { 1 - 3 } Febrile Seizure & $45(67.1)$ & $55(41.35)$ & \\
Fever without convulsion & $22(32.9)$ & $78(58.65)$ & 0.0005 \\
Total & $67(100)$ & $133(100)$ & \\
\hline
\end{tabular}

\section{Discussion}

In this study, the incidence of iron-deficiency anemia in the febrile convulsion group was obviously higher than the control group. Like our research, the study of Pisacane et al reported that anemia in the case group (30\%) was higher than in the hospital control group (14\%) and the healthy group (12\%) (Pisacane et al., 1996). In the study of Vaswani et al also, $68 \%$ of cases were iron deficient compared to $30 \%$ of the controls (Vaswani et al., 2009). In the study of Sadeghzadeh et al, although anemia was not common among febrile seizure patients, iron deficiency was more frequent in these patients (Sadeghzadeh et al., 2012). A study by Ur-Rahman and Billoo on 30 children with febrile convulsion and 30 children with other febrile diseases indicated that iron-deficiency anemia in the case group was significantly more common than in the control group (Ur-Rehman et al., 2005). A Kenyan case-control study as well as the meta-analysis of eight case-control studies that have examined the relationship between febrile seizures or acute seizures and iron deficiency suggested that iron deficiency may be associated with an increased risk of febrile seizures in children (Idro et al., 2010). Fever can worsen the effects of anemia or iron deficiency on the brain, and therefore cause convulsions. In addition, anemia can be associated with the degree of febrile disease, and patients with more severe symptoms may be affected by convulsions. But, febrile convulsion usually occurs at the onset of a febrile disease, before hemoglobin is reduced due to the infectious disease (Pisacane et al., 1996). In a study conducted in Thailand, the rate of thalassemic children with febrile convulsion was reported as being 4.4 times less than the general population of children. The researchers suggested that it might be due to higher levels and the role of iron in brain metabolism, which leads to less occurrence of febrile convulsion in those children (Auvichayapat et al., 2004). This study, of course, can simply assess its role in increasing the iron and in the reduction of febrile convulsions, and cannot be a desirable scale to measure iron-deficiency anemia and febrile convulsion. On the other hand, low risk of febrile convulsion in thalassemic patients could be due to several other clinical conditions that they may have. On the other hand, some studies have reported findings that are not similar to the result of this study. For example, in the study of Hartfield et al, iron deficiency was found to be $9 \%$ and $5 \%$ in the children of two groups of febrile convulsion and febrile without convulsion, respectively; and iron-deficiency anemia was found to be $6 \%$ and $4 \%$ in the former and latter groups, respectively (Hartfield et al., 2009). Again, in the study of Kobrinsky et al, the febrile convulsion group suffered less from iron deficiency. They concluded that iron deficiency could have a protective effect against febrile convulsions (Hartfield et al., 2009); and in the paper by Bidabadi, iron deficiency in the febrile convulsion group (44\%) was less than in the control group (48\%), but since there was no significant difference, the protective effect of iron deficiency against febrile convulsions was not confirmed (Bidabadi et al., 2009). The major causes that lead to different results between their and our studies may include not considering the effect of age in interpreting the tests for the diagnosis of iron deficiency, the difference in the age and number 
of samples, and difference in the diagnostic criteria of IDA between their and our studies. In the present study, all samples of the case group suffered from the febrile convulsion for the first time, but in most of the mentioned studies, some samples had a history of febrile convulsion.

According the findings of the present study, the incidence of iron deficiency in children suffering from fever and convulsion was observed to be more than that the fever without convulsion group. In conclusion, the findings suggest that low serum iron levels and the presence of anemia can serve as strengthening factors for the febrile seizures in children. Thus, iron deficiency can be added to the list of risk factors for febrile convulsions. Accordingly, children with febrile seizures are suggested to be monitored for diagnosis and treatment of iron-deficiency anemia. Furthermore, it is advisable to prescribe the iron supplements sooner and more carefully to children who have important and well-known risk factors for febrile convulsion, such as family history of febrile convulsion. It will be worthwhile to conduct a study to follow up children with iron deficiency, which stricken by the febrile convulsions after the treatment of iron deficiency, in terms of the recurrence rate of febrile convulsions.

\section{Conclusions}

The findings suggest that a considerable percentage of children having febrile seizure suffer from iron-deficiency anemia and low serum iron. This means the low serum iron and presence of anemia can serve as a reinforcing factor for the febrile seizure in children.

\section{References}

Amirsalari, S., Keihanidost, Z., Ahmadi, M., Sabouri, A., Kavemanesh, Z., \& Afshar, P. (2010). Relationship between Iron Deficiency Anemia and Febrile Seizures. Iran J Child Neurology, 14(1), 27-30.

Auvichayapat, P., Auvichayapat, N., Jedsrisuparp, A., Thinkhamrop, B., Sriroj, S., \& Piyakulmala, T. (2004). Incidence of Febrile Seizures in Thalassemic Patients. J Med Assoc Thai, 87(8), 970-973.

Bidabadi, E., \& Mashouf, M. (2009). Association between Iron Deficiency Anemia and First Febrile Convulsion: A Case-control Study. Seizure, 18, 347-351. http://dx.doi.org/10.1016/j.seizure.2009.01.008

Daoud, A. S., Batieha, A., Abu-Ekteish, F., Gharaibeh, N., Ajlouni, S., \& Hijazi, S. (2002). Iron Status: A Possible Risk Factor for the First Febrile Seizure. Epilepsia, 43(7), 740-743. http://dx.doi.org/10.1046/j. 1528-1157.2002.32501.x

Hartfield, D. S., Tan, J., Yager, J. Y., Rosychuk, R. J., Spady, D., Haines, C., \& Craig, W. R. (2009). The Association between Iron Deficiency and Febrile Seizures in Childhood. Clin Pediatr (Phila), 48(4), 420-6. http://dx.doi.org/10.1177/0009922809331800

Idro, R., Gwer, S., Williams, T. N., Otieno, T., \& Uyoga, S. (2010). Iron Deficiency and Acute Seizures: Results from Children Living in Rural Kenya and a Meta-analysis. PLOS ONE, 5(11), e14001. http://dx.doi.org/10. 1371/journal.pone.0014001

Jones, T., \& Jacobsen, S. J. (2007). Childhood Febrile Seizures: Overview and Implications. Int J Med Sci, 4(2), $110-4$.

Kheirkhah, D., \& Sharif, M. R. (2013). The rate of iron-deficiency anemia in febrile children with and without seizure in Kashan, 2012. Abstract Book of Ninth Annual Congress of Iranian Pediatric Infectious Diseases Society, December 4-6, Tehran Iran, 154-155.

Kliegman, R. M. (2011). Nelson Textbook of Pediatrics (19th ed.). W. B. Saunders Co.

Kobrinsky, N. L., Yager, J. Y., Cheang, M. S., \& Yatscoff, R. W. (1995). Tenenbein M. Does Iron Deficiency Raise the Seizure Threshold? J Child Neurol, 10(2), 105-9. http://dx.doi.org/10.1177/088307389501000207

Lozoff, B., Beard, J., Connor, J., Barbara, F., \& Georgieff, M. (2006). Long-lasting Neural and Behavioral Effects of Iron Deficiency in Infancy. Nutr Rev, 64, 34-43. http://dx.doi.org/10.1301/nr.2006.may.S34-S43

Momen, A., Nikfar, R., \& Karimi, B. (2010). Evaluation of Iron Status in 9-month to 5-year-old Children with Febrile Seizures: A Case-control Study in the South West of Iran. Iran J Child Neurology, 4(2), 45-50.

Oski, F. A., Brugnara, C., \& Nathan, D. G. (2008). A Diagnostic Approach to the Anemic Patients. In D. G. Nathan, \& S. H. Orkin (Eds.), Nathan and Oski's Hematology of Infancy and Childhood (7th ed.). W. B. Saunders Company.

Østergaard, J. R. (2009). Febrile Seizures. Acta Paediatr, 98(5), 771-3. http://dx.doi.org/10.1111/j.16512227.2009.01200.x 
Parks, Y. A., \& Wharton, B. A. (1989). Iron Deficiency and the Brain. Acta Paediatr Scand, Suppl 361, 71-77.

Pisacane, A., Sansone, R., Impagliazzo, N., Coppola, A., Rolando, P., \& D'Apuzzo, A. (1996). Iron Deficiency Anemia and Febrile Convulsions: Case-control Study in Children under 2 Years. BMJ, 313(7053), 343. http://dx.doi.org/10.1136/bmj.313.7053.343

Sadeghzadeh, M., Khoshnevis, P., \& Mahboubi, E. (2012). Iron Status and Febrile Seizure-A Case Control Study in Children Less Than 3 Years. Iran J Child Neurol, 6(4), 27-31.

Salehi Omran, M. R., Tamaddoni, A., Nasehi, M. M., Babazadeh, H., \& Alizadeh Navaei, R. (2009). Iron Status in Febrile Seizure: A Case-control Study. Iran J Child Neurology, 40-43.

Talebian, A., \& Momtazmanesh, N. (2007). Febrile Seizures and Anemia. Iran J Child Neurology, 31-33.

Ur-Rehman, N., \& Billoo, A. G. (2005). Association between Iron Deficiency Anemia and Febrile Seizures. $J$ Coll Physicians Surg Pak, 15(6), 338-40.

Vaswani, R. K., Dharaskar, P. G., Kulkarni, S., \& Ghosh, K. (2009). Iron Deficiency as a Risk Factor for First Febrile Seizure. Indian Pediatr, 47, 437-439. http://dx.doi.org/10.1007/s13312-010-0080-8

\section{Copyrights}

Copyright for this article is retained by the author(s), with first publication rights granted to the journal.

This is an open-access article distributed under the terms and conditions of the Creative Commons Attribution license (http://creativecommons.org/licenses/by/3.0/). 